\title{
Prognostic Value of Walk Distance, Work, Oxygen Saturation, and Dyspnea During 6-Minute Walk Test in COPD Patients
}

\author{
Rafael Golpe MD PhD, Luis A Pérez-de-Llano MD PhD, Lidia Méndez-Marote MD, \\ and Alejandro Veres-Racamonde MD
}

\begin{abstract}
BACKGROUND: Distance walked during the 6-min walk test (6MWT) predicts mortality in COPD. The body weight of the patient affects the work required to walk. Calculated work during the 6MWT (6MWT work) may account for differences in walk distance resulting from change in body weight. Thus, 6MWT work might be a better predictor of mortality than distance walked. This study was designed to test this hypothesis and to assess if other variables measured during the 6MWT, like continuous oximetry recording, offered additional prognostic information. METHODS: This was a retrospective analysis of prospectively collected data; 104 COPD patients were studied. 6MWT was performed in all cases. 6MWT work was calculated as body weight (in $\mathrm{kg}) \times$ distance walked (in $\mathrm{m}$ ). Receiver operating characteristic curves were used to assess the value of variables to predict mortality. Additional analysis was performed using Kaplan-Meier survival plots and Cox proportional hazards regression models. RESULTS: Mean follow-up was $590 \pm 472 \mathrm{~d}$. Eleven subjects $(10.6 \%)$ died. 6MWT work was not better than distance walked to predict mortality (area under the curve 0.77 for $6 \mathrm{MWT}$ work vs 0.80 for distance; difference $0.03,95 \%$ CI -0.05 to $0.12, P=.45$ ). Subjects who died had more dyspnea (measured using the Borg scale) after the 6MWT (8.5 vs 4.0, $P<.001)$, lower baseline $\mathrm{S}_{\mathrm{pO}}(85 \%$ vs $93 \%, P=.001)$, worse oxygen saturation during the 6MWT (mean $\mathrm{S}_{\mathrm{pO}}$ while walking $74.0 \%$ vs $86.6 \%, P=.02$ ) and walked less distance $(255 \mathrm{~m}$ vs $480 \mathrm{~m}, P=.001)$. On multivariate analysis, only $6 \mathrm{MWT}$ distance and dyspnea after the test correlated independently with mortality $(P=.005$ for both variables). CONCLUSIONS: 6MWT work was not more useful than 6MWT distance to predict mortality. The study confirms that 6MWT distance and dyspnea on exertion are key elements in prognostic evaluation in COPD, while the value of exercise oxygen desaturation is less clear. Key words: 6-min walk test; prognosis; mortality; pulmonary diseases; chronic obstructive; work capacity evaluation; oximetry. [Respir Care 2013; 58(8):1329-1334. (c) 2013 Daedalus Enterprises]
\end{abstract}

\section{Introduction}

COPD is an important cause of mortality. Several factors have been found to predict adverse outcome in this disease, like degree of dyspnea, exercise capacity, body

\footnotetext{
The authors are affiliated with Servicio de Neumología, Hospital Universitario Lucus Augusti, Lugo, Spain.

The authors have disclosed no conflicts of interest.

Correspondence: to: Rafael Golpe MD PhD, Servicio de Neumología, Hospital Universitario Lucus Augusti, Calle Doctor Ulises Romero ${ }^{\circ} 1$, 27003 Lugo, Spain. E-mail: rafael.golpe.gomez@sergas.es.
}

DOI: $10.4187 /$ respcare. 02290 mass index, and degree of airway obstruction, as measured using $\mathrm{FEV}_{1} \cdot{ }^{1}$ The 6 -min walk test (6MWT) is an easy to perform submaximal exercise test that reflects the functional exercise capacity in COPD patients, and the 6-min walk distance (6MWD) correlates strongly with mortality in this disease. ${ }^{2-4}$ Oxygen desaturation during the 6MWT might add modest additional prognostic information in COPD. ${ }^{4,5}$ However, measurement of oxygen saturation during the test is not a standardized procedure. ${ }^{6}$ In many cases, when oxygen saturation is determined, only punctual measurements are taken, and the examiner reports only whether the saturation falls below $90 \%$. Continuous oximetry recording during the 6MWT might offer a better estimate of gas exchange during exercise and thus might correlate better with prognosis. 
The body weight of the patient affects the work/energy required to perform the walk. ${ }^{7}$ As the $6 \mathrm{MWT}$ is intended to account for work, and work is determined by force and distance traveled, it would be logical to include force (body weight) as well as distance when assessing the results of the 6MWT. Carter et al suggested that calculated work (body weight $\times$ distance walked) during the 6MWT (6MWT work) may account for differences in 6MWD resulting from change in body weight, and this parameter would therefore improve the usefulness of the test. ${ }^{7} \mathrm{We}$ hypothesized that $6 \mathrm{MWT}$ work might be a better predictor of mortality in COPD patients than distance walked. This study was designed with the main objective of testing this hypothesis. Secondary objectives were to determine if other parameters measured during the 6MWT offered additional prognostic information, with a special focus on variables derived from continuous oximetry recording during exercise.

\section{Methods}

\section{Study Design and Subjects}

This was a retrospective analysis of prospectively collected data. Subjects were recruited from the respiratory medicine service of the University Hospital Lucus Augusti. The study population included patients who performed the 6MWT as part of their clinical evaluation, according to the criteria of their attending clinician. Inclusion criteria were age $>40$ years, $\mathrm{FEV}_{1} / \mathrm{FVC}<70 \%$ of predicted, postbronchodilator $\mathrm{FEV}_{1}<80 \%$ of predicted, and clinical stability for at least 8 weeks. Exclusion criteria were diagnosis of asthma, malignant disorders, uncontrolled heart failure, coexisting respiratory disorders (eg, kyphoscoliosis), and inability to perform spirometry and/or 6MWT. Approval for the use of the data was obtained from our local ethics committee.

Spirometry was performed (Sibelmed Datospir 120 spirometer, Sibel, Barcelona, Spain), according to the American Thoracic Society/European Respiratory Society consensus guidelines, ${ }^{8}$ and using the European Respiratory Society predicted values. ${ }^{9}$ The 6 MWT was performed according to the American Thoracic Society statement, in a $30 \mathrm{~m}$ corridor. ${ }^{6}$ For subjects who were already on longterm oxygen therapy, the 6MWT was performed with supplemental oxygen at their usual flow. Continuous pulse oximetry was recorded during the test, using a wrist oximeter with a finger probe (Pulsox 3i, Minolta, Ramsey, New Jersey). Pulse oximetry variables were calculated using computer software (Pulsox $\mathrm{S}_{\mathrm{pO}_{2}}$ analysis software DS-3, Minolta, Ramsey, New Jersey). We registered the following variables: total distance walked, resting $\mathrm{S}_{\mathrm{pO}_{2}}$ before walking, mean and lowest $\mathrm{S}_{\mathrm{pO}_{2}}$ during the test, dyspnea, and leg fatigue after the test, as measured using

\section{QUICK LOOK}

\section{Current knowledge}

Six-min walk distance (6MWD) and dyspnea on exertion are key elements of prognosis in patients with COPD; 6MWD predicts mortality risk. Body weight impacts 6MWD, and use of patient weight and distance to determine the work during the 6-min walk test (6MWT) may be useful.

\section{What this paper contributes to our knowledge}

6MWT work was not a better predictor of mortality than was 6MWD.

the modified Borg scale, and cumulative percentages of time with $\mathrm{S}_{\mathrm{pO}_{2}}<90 \%$ while walking. 6MWT work was calculated as body weight (in $\mathrm{kg}$ ) $\times$ distance walked (in $\mathrm{m}$ ).

\section{Statistical Analysis}

The primary end point was the time from the date of the 6MWT to the date of death. A census of subjects was taken at the end of the study. Vital status, ascertained as of July 2012, was determined by review of electronic patient charts. Normal distribution of data was assessed using the D'Agostino-Pearson test. Data are expressed as mean \pm SD (normal distribution) or as median (interquartile range) (non-normal distribution) for continuous variables, and as percentages for categorical variables. Correlation between variables was assessed with the Pearson or Spearman correlation coefficient, as appropriate. For continuous variables, comparisons between survivors and non-survivors were made using the unpaired $t$ test or the Wilcoxon ranksum test, as appropriate. The chi-square test was used for categorical variables. Receiver operating characteristic (ROC) curves were constructed to assess the value of different variables to predict mortality. Differences in areas under the different curves were calculated using the method of DeLong et al. ${ }^{10}$ Kaplan-Meier cumulative survival plots were obtained for variables with the highest areas under the ROC curves. Kaplan-Meier plots were constructed for values above and below the value with the best combination of sensitivity and specificity in ROC analysis. The log rank test was used to compare survival curves. Univariate and multivariate Cox proportional hazards regression models were used to calculate hazard ratios and 95\% CIs. Multivariate analyses were performed using a stepwise forward regression model in which each variable with $P \leq .10$ on univariate analysis was entered into the model. To avoid collinearity, oxygen saturation variables were introduced separately. The $P$ values were 2 -sided, and $P<.05$ was considered statistically significant. 
Table 1. Differences Between Survivors and Non-survivors

\begin{tabular}{|c|c|c|c|}
\hline & $\begin{array}{c}\text { Non-survivors } \\
n=11\end{array}$ & $\begin{array}{c}\text { Survivors } \\
n=93\end{array}$ & $P$ \\
\hline Male, no. (\%) & $8(72.7)$ & $74(79.5)$ & .89 \\
\hline Age, mean $\pm \mathrm{SD}$ y & $66.3 \pm 9.8$ & $63.4 \pm 11.7$ & .39 \\
\hline $\mathrm{FEV}_{1} \%$ & $29.0(26.0-60.0)$ & $42.0(30.0-61.0)$ & .32 \\
\hline $\mathrm{BMI}$, mean $\pm \mathrm{SD} \mathrm{kg} / \mathrm{m}^{2}$ & $26.7 \pm 2.6$ & $27.3 \pm 4.7$ & .64 \\
\hline \multicolumn{4}{|l|}{ Borg dyspnea score } \\
\hline Baseline & $0(0-2.5)$ & $0(0-0)$ & .58 \\
\hline After 6MWT & $8.5(6.5-10.0)$ & $4.0(2.0-6.0)$ & $<.001$ \\
\hline Borg fatigue score after $6 \mathrm{MWT}$ & $1.5(0-2.5)$ & $1.5(0-40.0)$ & .87 \\
\hline Baseline $\mathrm{S}_{\mathrm{pO}_{2}}, \%$ & $85.0(80.5-91.7)$ & $93.0(90.0-95.0)$ & .001 \\
\hline Mean $\mathrm{S}_{\mathrm{pO}_{2}}$ during $6 \mathrm{MWT}, \%$ & $74.0(66.0-89.6)$ & $86.6(82.1-91.3)$ & .02 \\
\hline Lowest $\mathrm{S}_{\mathrm{pO}_{2}}$ during $6 \mathrm{MWT}, \%$ & $70.0(54.5-79.2)$ & $83.0(74.0-88.0)$ & .004 \\
\hline Percent of time with $\mathrm{S}_{\mathrm{pO}_{2}}<90 \%$ during 6MWT, \% & $98.4(57.7-100)$ & $81.6(9.8-93.8)$ & .03 \\
\hline 6MWD, m & $255.0(192.5-393.5)$ & $480.0(373.7-540.0)$ & .001 \\
\hline $6 \mathrm{MWT}$ work, mean $\pm \mathrm{SD}$ & $21,281.0 \pm 10,058.3$ & $33,419.5 \pm 12,486.8$ & .002 \\
\hline \multicolumn{4}{|l|}{$\begin{array}{l}\text { Values are median (IQR), except where otherwise indicated. } \\
\text { BMI }=\text { body mass index } \\
6 \mathrm{MWT}=6 \text {-min walk test } \\
6 \mathrm{MWD}=6 \text {-min walk distance } \\
\text { 6MWT work = work during the 6MWT }\end{array}$} \\
\hline
\end{tabular}

Table 2. Correlations Between 6MWT Distance and 6MWT Work and Other Variables

\begin{tabular}{|c|c|c|c|c|}
\hline & \multicolumn{2}{|c|}{ 6MWD } & \multicolumn{2}{|c|}{ 6MWT Work } \\
\hline & $\mathrm{R}(95 \% \mathrm{CI})$ & $P$ & $\mathrm{R}(95 \% \mathrm{CI})$ & $P$ \\
\hline $\begin{array}{l}\text { Percent of time with } \mathrm{S}_{\mathrm{pO}_{2}}<90 \% \\
\text { during } 6 \mathrm{MWT}\end{array}$ & $-0.28(-0.45$ to -0.10$)$ & .004 & $-0.18(-0.36,0.01)$ & .054 \\
\hline Mean $\mathrm{S}_{\mathrm{pO}_{2}}$ during $6 \mathrm{MWT}$ & $0.34(0.16-0.50)$ & $<.001$ & $0.24(0.05-0.42)$ & .01 \\
\hline Lowest $\mathrm{S}_{\mathrm{pO}_{2}}$ during $6 \mathrm{MWT}$ & $0.37(0.19-0.53)$ & $<.001$ & $0.30(0.11-0.47)$ & .003 \\
\hline $\mathrm{FEV}_{1}$ & $0.33(0.15-0.49)$ & $<.001$ & $0.39(0.21-0.55)$ & $<.001$ \\
\hline Age & $-0.37(-0.52$ to -0.19$)$ & $<.001$ & $-0.23(-0.40$ to -0.04$)$ & .02 \\
\hline Body mass index & $-0.02(-0.21$ to 0.17$)$ & .81 & & \\
\hline Borg dyspnea score after 6MWT & $-0.32(-0.49$ to -0.13$)$ & .002 & $-0.29(-0.46$ to -0.10$)$ & .003 \\
\hline Borg fatigue score after $6 \mathrm{MWT}$ & $-0.009(-0.20$ to 0.19$)$ & .93 & $-0.14(-0.33$ to 0.05$)$ & .15 \\
\hline
\end{tabular}

\section{Results}

We included 104 subjects, of whom 82 (78.8\%) were male. The mean age was $63.8 \pm 11.5$ years. The mean $\mathrm{FEV}_{1} \%$ was $45.6 \pm 19.9 \%$. Sixty-five subjects $(62.5 \%)$ had $\mathrm{FEV}_{1} \%<50 \%$. Baseline $\mathrm{S}_{\mathrm{pO}_{2}}$ was $<90 \%$ in 25 cases $(24 \%)$, and $<85 \%$ in $7(6.7 \%)$. The subjects were followed up for $590 \pm 472$ days after the 6MWT. Eleven subjects $(10.6 \%)$ died during the follow-up. Median dyspnea and leg fatigue score after the test were, respectively: $4.5(2-6)$ and $1.5(0-4)$. Table 1 shows the differences between survivors and non-survivors. The subjects who died had more dyspnea after the 6MWT, lower baseline
$\mathrm{S}_{\mathrm{pO}_{2}}$, worse oxygen saturation parameters during the 6MWT, and walked less distance. Table 2 shows the correlations between 6MWD, 6MWT work, and the different variables. For most variables, correlation with 6MWT was somewhat better than with 6MWT work. Table 3 shows the areas under the ROC curves for the different parameters studied. Only 6MWD, baseline $\mathrm{S}_{\mathrm{pO}_{2}}$, and dyspnea after the 6MWT achieved an adequate $(\mathrm{eg}, \geq 0.8)$ area under the curve. Pair-wise comparison of the areas under the ROC curves for these variables did not show significant differences between them (data not shown). Also, the area under the curve for 6MWT work was not significantly different than that for 6MWD (difference 0.03, 95\% CI 
Table 3. Area Under the Receiver Operating Characteristic Curve

\begin{tabular}{lcc}
\hline \hline & AUC & $95 \% \mathrm{CI}$ \\
\hline 6MWD & 0.80 & $0.71-0.87$ \\
6MWT work & 0.77 & $0.68-0.85$ \\
Baseline $\mathrm{S}_{\mathrm{pO}_{2}}$ & 0.80 & $0.71-0.87$ \\
Percent of time with $\mathrm{S}_{\mathrm{pO}_{2}}$ & 0.71 & $0.61-0.79$ \\
$\quad<90 \%$ during 6MWT & & \\
Mean $\mathrm{S}_{\mathrm{pO}_{2}}$ during 6MWT & 0.73 & $0.64-0.81$ \\
Lowest $\mathrm{S}_{\mathrm{pO}_{2}}$ during 6MWT & 0.78 & $0.69-0.86$ \\
FEV & $\%$ \\
Age & 0.61 & $0.51-0.71$ \\
Body mass index & 0.53 & $0.43-0.63$ \\
Borg dyspnea score after 6MWT & 0.54 & $0.44-0.64$ \\
& 0.88 & $0.80-0.94$ \\
AUC $=$ area under the curve & & \\
6MWD $=6$-min walk distance & & \\
6MWT work = work during the 6-min walk test & & \\
\end{tabular}

-0.05 to $0.12, P=.45)$. Better combination of sensitivity and specificity for 6MWD was found at a cutoff value of $395 \mathrm{~m}$. For baseline $\mathrm{S}_{\mathrm{pO}_{2}}$ the best cutoff point was $86 \%$. For dyspnea the most useful value of the Borg scale was 7 (Table 4). Figures 1, 2, and 3 show the Kaplan-Meier survival curves for cases below and above these values, which were significantly different for all variables (6MWD $P<.001$, baseline $\mathrm{S}_{\mathrm{pO}_{2}} P=.002$, dyspnea $\left.P<.001\right)$. Table 5 shows the results of univariate and multivariate Cox proportional hazards analysis of the relation between clinical variables and all-cause mortality. On multivariate analysis, only 6MWD and post-6MWT dyspnea score correlated independently with mortality.

\section{Discussion}

The main results of the present study are: 6MWT work was not better than 6MWD to predict mortality; both 6MWD and dyspnea after the 6MWT correlated with mortality; and desaturation during 6MWT did not provide additional prognostic information.

Carter et al found, through ROC analysis, that 6MWT work had a better combination of sensitivity and specific-

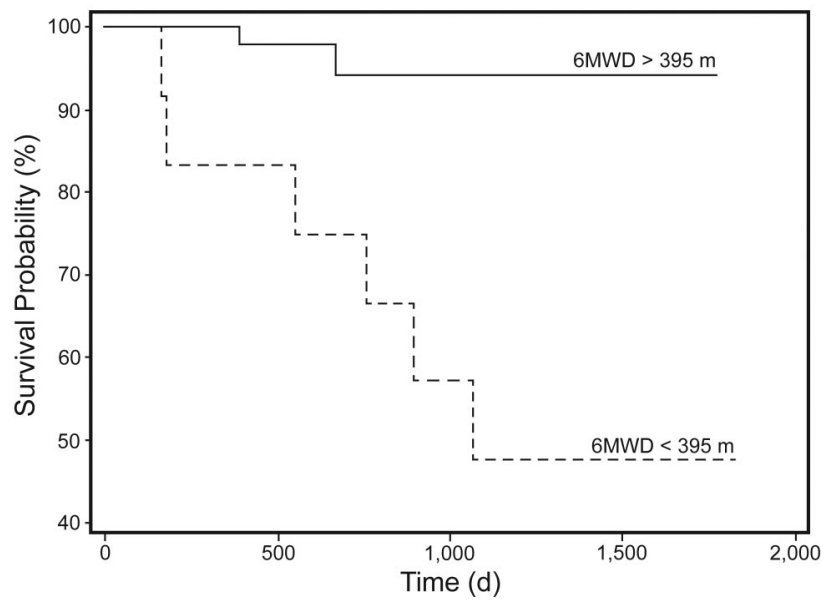

Fig. 1. Kaplan-Meier survival curves for subjects who walked more than versus less than $395 \mathrm{~m}$ in the 6-min walk test.

ity than 6MWD to discriminate between low versus high exercise work capacity in COPD patients. ${ }^{7}$ Exercise capacity is an important outcome predictor in COPD, ${ }^{1,11}$ so it would be expected that 6MWT work would predict mortality better than 6MWD. On the contrary, the present study found a lower area under the ROC curve for 6MWT work than for 6MWD, although the difference did not reach significance. Differences in study populations might account for this discrepancy. Of note, the leg fatigue scores in the study by Carter et al were greater than the dyspnea scores, suggesting that leg fatigue contributed significantly to exercise limitation in their subjects. ${ }^{7}$ By contrast, the present study found greater dyspnea scores. It is also worth mentioning that, in the study by Carter et al, 6MWT work correlated better with pulmonary function indices and gas exchange variables than did $6 \mathrm{MWD},{ }^{7}$ while we found the opposite results.

Measurement of oxygen saturation during the 6MWT is not a standardized procedure. The current guidelines consider oximetry optional during the $6 \mathrm{MWT} .6$ In the present study, oxygen desaturation during the 6MWT correlated with mortality. However, in the multivariate analysis it did not remain as an independent predictor. These results agree

Table 4. Values With the Best Combination of Sensitivity and Specificity in Receiver Operating Characteristic Curve Analysis

\begin{tabular}{|c|c|c|c|c|c|}
\hline & $\begin{array}{l}\text { Cutoff } \\
\text { Value }\end{array}$ & $\begin{array}{c}\text { Sensitivity } \\
(95 \% \text { CI })\end{array}$ & $\begin{array}{c}\text { Specificity } \\
(95 \% \text { CI })\end{array}$ & $\begin{array}{l}\text { Positive } \\
\text { Predictive } \\
\text { Value }\end{array}$ & $\begin{array}{c}\text { Negative } \\
\text { Predictive } \\
\text { Value }\end{array}$ \\
\hline 6MWD & $395 \mathrm{~m}$ & $81.8(48.2-97.2)$ & $72.04(61.8-80.9)$ & 25.7 & 97.1 \\
\hline Baseline $\mathrm{S}_{\mathrm{pO}_{2}}$ & $86 \%$ & $63.6(30.9-88.8)$ & $90.3(82.4-95.5)$ & 43.7 & 95.5 \\
\hline Borg dyspnea score after $6 \mathrm{MWT}$ & 7 & $75.0(35.0-96.1)$ & $92.2(84.6-96.8)$ & 46.2 & 97.6 \\
\hline
\end{tabular}

$\overline{6 \mathrm{MWD}=6 \text {-min walk }}$ distance

$6 \mathrm{MWT}=6$-min walk test 


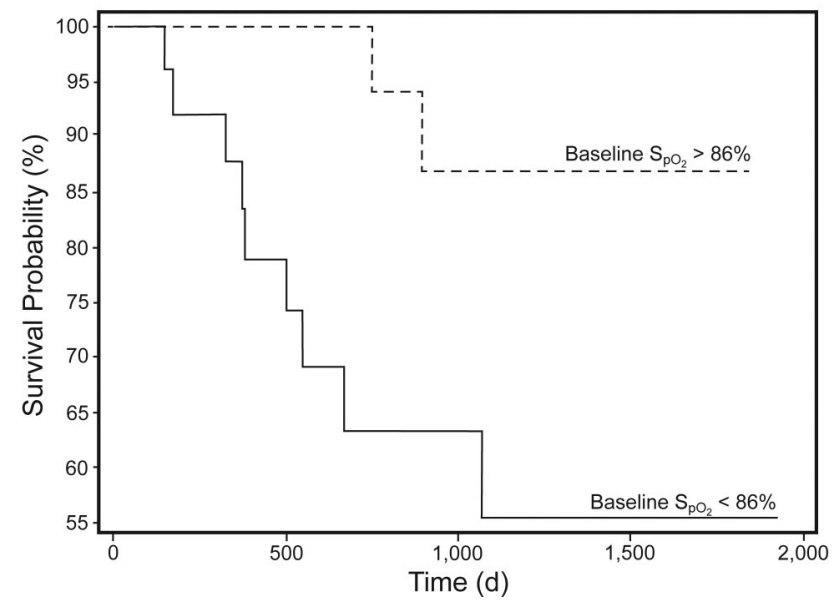

Fig. 2. Kaplan-Meier survival curves for subjects with baseline $\mathrm{S}_{\mathrm{pO}_{2}}$ higher than versus lower than $86 \%$.

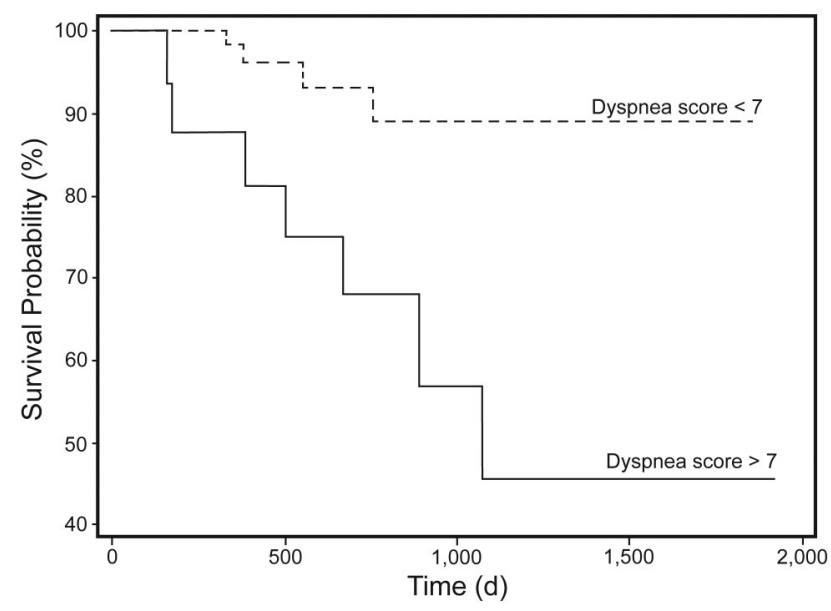

Fig. 3. Kaplan-Meier survival curves for subjects with Borg dyspnea scores lower than versus higher than 7. with the study by Casanova et al, ${ }^{4}$ despite using a different methodology. Casanova et al excluded from the analysis of oxygen desaturation during the test those subjects with resting $\mathrm{S}_{\mathrm{pO}_{2}}<90 \%$ on room air. By contrast, we did not exclude such cases from our analysis, although we added oxygen while performing the test to those subjects who were already on long-term oxygen therapy. Taken together, the results from the study by Casanova et al and those from the present study suggest that the prognostic information provided by oximetry during the $6 \mathrm{MWT}$ is modest at best. Therefore, the results of our study do not support the need to perform oximetry systematically during the test.

Takigawa et al, ${ }^{5}$ in contrast, found that oxygen desaturation was an independent predictor of mortality. They found no correlation between oxygen desaturation and 6MWD. In our study there was a significant correlation between oximetry parameters and 6MWD. This might explain why oxygen saturation was rejected as an independent predictor of mortality in the multivariate analysis.

It is interesting that dyspnea after the 6MWT correlated independently with mortality and, of all the variables studied, exhibited the largest area under the ROC curve. It is known that dyspnea is an important predictor of mortality in COPD. ${ }^{12}$ Dyspnea during activities of daily living, measured with the modified Medical Research Council (MMRC) dyspnea scale, is an essential component of the BODE (body mass index, air-flow obstruction, dyspnea, exercise capacity) index, which is, in turn, a powerful predictor of prognosis in this disease. ${ }^{1}$ Due to the limitations in design of our study, we did not know the MMRC dyspnea scale scores for all the subjects, so we cannot assess if dyspnea after the 6MWT offers additional prognostic information, compared with the more commonly

Table 5. Results of Univariate and Multivariate Cox Proportional Hazards Analysis of the Relation Between Clinical Variables and All-Cause Mortality

\begin{tabular}{|c|c|c|c|c|}
\hline & \multicolumn{2}{|c|}{ Univariate } & \multicolumn{2}{|c|}{ Multivariate } \\
\hline & $\begin{array}{l}\text { Hazard Ratio } \\
\quad(95 \% \mathrm{CI})\end{array}$ & $P$ & $\begin{array}{l}\text { Hazard Ratio } \\
(95 \% \mathrm{CI})\end{array}$ & $P$ \\
\hline 6MWD & $0.99(0.99-1.00)$ & .003 & $0.99(0.99-1.00)$ & .005 \\
\hline $\begin{array}{l}\text { Percent of time with } \mathrm{S}_{\mathrm{pO}_{2}} \\
<90 \% \text { during 6MWT }\end{array}$ & $1.01(1.00-1.03)$ & .35 & NA & NA \\
\hline Mean $\mathrm{S}_{\mathrm{pO}_{2}}$ during $6 \mathrm{MWT}$ & $0.94(0.89-1.00)$ & .02 & NA & NA \\
\hline Baseline $\mathrm{S}_{\mathrm{pO}_{2}}$ & $0.91(0.86-0.97)$ & .002 & NA & NA \\
\hline Lowest $\mathrm{S}_{\mathrm{pO}_{2}}$ during $6 \mathrm{MWT}$ & $0.96(0.93-1.00)$ & .03 & NA & NA \\
\hline $\mathrm{FEV}_{1}$ & $0.99(0.95-1.03)$ & .52 & NA & NA \\
\hline Borg dyspnea score after 6MWT & $1.55(1.14-2.12)$ & .001 & $1.55(1.14-2.12)$ & .005 \\
\hline \multicolumn{5}{|l|}{$\begin{array}{l}6 \mathrm{MWD}=6 \text {-min walk distance } \\
6 \mathrm{MWT}=6 \text {-min walk test }\end{array}$} \\
\hline
\end{tabular}


used MMRC dyspnea scale. However, a previous study found a correlation between dyspnea during daily living measured with the MMRC dyspnea scale and dyspnea after the 6MWT using the Borg scale. ${ }^{13}$ In that study the MMRC dyspnea scores correlated better than did the Borg dyspnea scores with changes in inspiratory capacity (used as a marker of dynamic hyperinflation).

The present study has several limitations, the most obvious being its retrospective design and relatively small sample size. We did not include a random sample from patients along all the spectrum of disease severity, so the study was vulnerable to selection bias. Actually, the 6MWT is usually performed in patients with more severe disease. Mean $\mathrm{FEV}_{1}$ was $45 \%$ of predicted, indicating that our cases indeed had advanced disease. The design of the study did not allow us to evaluate other predictors of mortality in COPD, like the BODE index, although this was not the main objective of the study. Also, few women were included in the study, so we cannot exclude the possibility of sex differences in the prognostic value of any variable.

\section{Conclusions}

In summary, 6MWT work was not more useful than 6MWD to predict mortality. The present study confirms that 6MWD and dyspnea on exertion are key elements in prognostic evaluation in COPD, while the value of exercise oxygen desaturation is less clear. Whether dyspnea after exercise, measured with the Borg scale, offers better prognostic information than other variables in COPD merits further evaluation.

\section{REFERENCES}

1. Celli BR, Cote C, Marin JM, Casanova C, Montes de Oca M, Mendez RA, et al. The body mass index, airflow obstruction, dyspnea, exercise performance (BODE) index in chronic obstructive pulmonary disease. N Engl J Med 2004;350(10):1005-1012.

2. Pinto-Plata VM, Cote C, Cabral H, Taylor J, Celli BR. The 6-min walk distance: change over time and value as a predictor of survival in severe COPD. Eur Respir J 2004;23(1):28-33.

3. Martinez FJ, Foster G, Curtis JL, Criner G, Weinmann G, Fishman A, et al; NETT Research Group. Predictors of mortality in patients with emphysema and severe airflow obstruction. Am J Respir Crit Care Med 2006;173(12):1326-1334.

4. Casanova C, Cote C, Marín JM, Pinto-Plata V, de Torres JP, Aguirre-Jaime A, et al. Distance and oxygen desaturation during the 6-min walk test as predictors of long-term mortality in patients with COPD. Chest 2008;134(4):746-752.

5. Takigawa N, Tada A, Soda R, Date H, Yamashita M, Endo S, et al. Distance and oxygen desaturation in 6-min walk test predict prognosis in COPD patients. Respir Med 2007;101(3):561-567.

6. ATS statement: guidelines for the six-minute walk test. Am J Respir Crit Care Med 2002;166(1):111-117.

7. Carter R, Holiday DB, Nwasuruba C, Stocks J, Grothues C, Tiep B. 6-minute walk work for assessment of functional capacity in patients with COPD. Chest 2003;123(5):1408-1415.

8. Miller MR, Hankinson J, Brusasco V, Burgos F, Casaburi R, Coates A, et al. Standardisation of spirometry. Eur Respir J 2005;26(2):319-38.

9. Quanjer PH, Tammeling GJ, Cotes JE, Pedersen OF, Peslin R, Yernault JC. Lung volumes and forced expiratory flows. Report working party standardization of lung function tests, European community for steel and coal. Official statement of the European respiratory society Eur Respir J 1993;16(Suppl):5-40.

10. DeLong ER, DeLong DM, Clarke-Pearson DL. Comparing the areas under two or more correlated receiver operating characteristic curves: a nonparametric approach. Biometrics 1988;44(3):837-845.

11. Oga T, Tsukino M, Hajiro T, Ikeda A, Nishimura K. Predictive properties of different multidimensional staging systems in patients with chronic obstructive pulmonary disease. Int J Chron Obstruct Pulmon Dis 2011;6:521-526.

12. Nishimura K, Izumi T, Tsukino M, Oga T. Dyspnea is a better predictor of 5-year survival than airway obstruction in patients with COPD. Chest 2002;121(5):1434-1440.

13. Marin JM, Carrizo SJ, Gascon M, Sanchez A, Gallego B, Celli BR. Inspiratory capacity, dynamic hyperinflation, breathlessness, and exercise performance during the 6-minute-walk test in chronic obstructive pulmonary disease. Am J Respir Crit Care Med 2001;163(6): 1395-1399. 